\title{
UNA PIZCA DE SENTIDO. ACERCA DE ENTRE CELAN Y HEIDEGGER DE PABLO OYARZÚN
}

\author{
Juan Manuel Garrido \\ Universidad de Chile \\ juanmanu@ctcreuna.cl
}

\begin{abstract}
Resumen
En el siguiente artículo, me propongo explicar y analizar las que me parecen ser las tesis filosóficas principales del libro de Pablo Oyarzún Entre Celan y Heidegger, así como proponer algunas pistas para reflexionar en torno a problemáticas relevantes que esta obra contribuye a identificar y a formular. Dos son los principales argumentos que elaboro con el fin de llevar a cabo este trabajo. El primero concierne el concepto de "sentido", que Oyarzún intenta desarrollar en tensión con lo que entiende ser la "lectura hermenéutica" de la poesía de Celan (y de la poesía en general), que presupone según él que el poema, como cualquier otra creación de lenguaje, quiere decir algo y por lo tanto es portador de significados accesibles para la comprensión. Frente a eso, Oyarzún opone la inaccesible insignificancia del lenguaje poético, la "pizca" de sentido cuya propiedad fundamental consiste en irrumpir en medio de la circulación y transmisión de sentido y resistir a la comprensión - pero, de ese modo, la posibilita como comprensión, dado que solo lo que la resiste logra ponerla en movimiento. El segundo argumento concierne a la significación del "dolor", que precisamente no ha de poseer ninguna "significación", so pena de ser neutralizado y obliterado como dolor. Solo la absurda crudeza del dolor, a título de acontecimiento traumático que retorna excediendo la identidad temporal de una conciencia colectiva -es la función de la "data" en la poesía de Celan-, puede dar origen a una memoria y a una historia auténticas.
\end{abstract}

Palabras clave: sentido, poesía, absurdo, dolor, singularidad.

\section{Abstract}

This paper seeks to elaborate and analyze the main philosophical import of Pablo Oyarzun's book, Entre Celan y Heidegger. Along the way, I will hint at possibilities for thinking through certain key issues that have been identified and formulated by the author. In doing so, this essay will follow two major lines of argumentation. The first trajectory will consider the concept of "sense" as it is exhibited in Oyarzun's discussion of "hermeneutic readings" of Celan's poetry in particular (and in readings of poetry more generally). According to Oyarzún, hermeneutic readings operate under the assumption that a given poem, like any other linguistic creation, possesses a definite meaning and signifies in a way that is accessible to the understanding. In response, Oyarzun elaborates the inaccessible insignificance at work in poetic language. The primary function of 
this insignificance can be seen in the way it bursts open the circuit of sense, thereby resisting the understanding -and, as will be seen, only that which resists the understanding can in turn put it into play. The second trajectory will then consider the meaning of "suffering" as something that must be deprived of signification if it is to overcome being neutralized and obliterated. Indeed, only the traumatic event of absurd suffering is tenacious enough to return and exceed the temporal identity of collective consciousness (and here one could consider the phenomenon of "dating" in Celan's poems). Finally, I would like to suggest that it is only with suffering that authentic memory and history arise.

KEYwords: Sense, poetry, absurdity, suffering, singularity.

$\overline{\mathrm{RA}}$ Sobre Celan y Heidegger existe, hace buen tiempo en el campo de la filosofía y de los estudios literarios contemporáneos, una importante tradición de comentarios, que incluye a autores de la talla de H.-G. Gadamer, J. Derrida, J. Bollack, Ph. Lacoue-Labarthe, E. Levinas, P. Szondi, W. Hamacher. Es ya un mérito del libro de Oyarzún, y no menor, el que ofrezca al lector hispanohablante la posibilidad de enterarse de esa discusión. Esto ha exigido, de partida, una cuidadosa labor de traducción. No es para ostentar su reconocido talento de traductor que Oyarzún advierte que todas las versiones españolas de las citas que contiene el libro son suyas (incluidas, desde luego, las de los poemas de Celan) $(10)^{1}$. Decidir versiones o modificar las ya existentes (por ejemplo, de Heidegger) es necesario cada vez que uno se pone ante la tarea de volver idiomáticamente consistente y comprensible, en el marco de una argumentación filosófica, una conceptualidad originada y cultivada en otras lenguas. No me parece exagerado decir -el autor sería el primero en suscribirlo- que en las traducciones de "citas" de Heidegger o Derrida se decide más que una política editorial: se decide en buena medida la posibilidad y el porvenir mismos del pensamiento que se está proponiendo. Este libro de Oyarzún, a diferencia de muchos libros de filosofía que se publican en español, no hay que retraducirlo mentalmente al francés, al inglés o al alemán para hacerlo inteligible.

Pero la pertinencia de Entre Celan y Heidegger no se limita a realizar este trabajo de transmisión. El autor ofrece una lectura propia de la poesía y pensamiento poético celanianos, siempre en tensión con preguntas que se originan frecuentando el pensamiento de Heidegger. No me refiero a que Oyarzún avance una interpretación personal o nueva sobre la relación entre Celan y Heidegger, una interpretación que añada algo a las otras interpretaciones ya existentes, por ejemplo, a las de Gadamer o Derrida. Oyarzún se esfuerza por formular su experiencia singular con esa poesía, sin limitarse a subsumirla a los tópicos universales y disponibles que han guiado la discusión existente. Leer e interpretar -y esto será doctrina en este libro- es ser capaz de

1 Entre Celan y Heidegger, Santiago: Metales Pesados, 2005. Todas las citas que contiene este artículo pertenecen a esta obra. 
decidir el sentido de un texto sin obliterar su singularidad a través de universales que nos releven de la tarea de comunicarla en cuanto que pura, acaso incomunicable, singularidad. Leer es ser capaz de enseñar, de mostrar o iluminar lo irreductible de una singularidad. ¿No es eso -la incomunicable singularidad de su experiencia- lo que constituye la esencia de un texto poético, aquí el de Celan? ¿No es por eso que decimos de los textos literarios que son "inagotables", que la exigencia de leerlos siempre insiste y retorna, a pesar de sus interpretaciones, o mejor, con ellas, por encima o por detrás de ellas? "Sería lícito", dice Oyarzún, "que el lector retrucara pidiendo saber qué es lo que a fin de cuentas he tratado de añadir a esa copiosa literatura [sobre Celan y Heidegger]. Diré que sólo ha sido un afán por enseñar lo que creo es la singularidad, a mis ojos decisiva, de la poesía y pensamiento poético de Celan" (133).

Entre Celan y Heidegger no ofrece un estudio comparativo de ambos autores a la luz de un repertorio de temas o problemas definidos con antelación y luego sobrepuestos a los textos analizados. Celan y Heidegger tampoco son los casos ejemplares de una problemática general, por ejemplo de la relación entre "literatura" ("poesía", "arte" o "mito") y "filosofía" ("pensar", "ciencia" o "saber"). Es interesante notar que el libro entero se aboca, minuciosamente, a destruir todo presupuesto de este tipo, todo horizonte común entre Celan y Heidegger. ¿Desde dónde podría elaborarse una comparación entre Celan y Heidegger, si ambos llevan al límite el problema del lenguaje y del pensamiento, si en ambos el sentido mismo de lo que llamamos "palabra", "poema", "existencia", "ser", "lugar", "verdad", "filosofía", "literatura", "sentido", queda rigurosamente abierto como pregunta radical? Cada vez que Celan y Heidegger parecen converger en algún tema común (por ejemplo "Lugar", "Arte", "Lenguaje", "Dolor"), Oyarzún se dedica a radicalizar las diferencias que los separan hasta volverlas insuprimibles. Pero no se trata tampoco de ofrecer una lectura de uno en su indiferente distancia respecto del otro, sino más bien de leer al uno desde el otro, desde su inconmensurable diferencia respecto del otro. Se trata de leer a uno contra el otro, a partir del otro, a través del otro, de modo tal que, desde esa alteridad, se pueda ir perfilando la singularidad de cada uno. Entre Celan y Heidegger hay "tirantez y tironeo incesantes, con amagos de proximidad que sorprenden y bruscos apartamientos" (133). Es por eso que el "entre", en lugar de ser una suerte de síntesis de esas singularidades diferentes, es un lugar antitético en que ambos autores se juntan en la medida misma en que se separan. La vecindad de Celan y Heidegger "carece de localidad: no tiene un dónde"; se trata de una "vecindad que se da en un espacio inconmensurable -un espacio, el de una lengua, que es experimentada de modos radicalmente diferentes (...)" (63).

Entre sí, Celan y Heidegger se muestran de modo distinto a como serían leídos cada uno por su cuenta. Es importante notarlo porque esto explica que uno se encuentre a veces con figuras poco familiares de estos autores. Oyarzún, de quien se sabe cuánto ha contribuido a la recepción, difusión y comentario del pensamiento heideggeriano en el medio hispanohablante, no siempre parece muy interesado en ser exhaustivo al reconstruir la doctrina del filósofo o al dar cuenta de los comentarios pertinentes (aunque en este libro pesa sobre todo la recepción que ha tenido Heidegger en Francia a través de Derrida, Levinas y Lacoue-Labarthe, para citar a autores que 
además han ofrecido lecturas importantes de Celan). Cada vez que el autor nos reseñe algún aspecto del pensamiento de Heidegger, será, como decía, enfocándolo desde la lectura de Celan y de lo que se vea en juego allí. Esto también explica que Oyarzún no siempre busque extraer las consecuencias que tienen, para la exégesis del pensador, las pistas que él mismo abre y descubre en sus análisis. Concentrado en "porfiar" (la palabra es suya) en el "entre", "el libro ha tenido que quedar abierto en sus extremos" (8). En otras palabras, las figuras de Celan y Heidegger quedan por venir, "en la palabra / venidera", para decirlo con dos versos de "Todtnauberg", en más de una ocasión comentados en el libro. $\mathrm{Y}$ es en cierta forma al lector a quien corresponde la tarea de hacerlas venir.

El primer capítulo, "Diálogo", se abre con un análisis de la pieza recién citada, “Todtnauberg", escrita por Celan tras la visita a Heidegger en su cabaña durante el verano de 1967. La lectura de ese poema condensa la problemática del libro. Conforme a lo que he indicado anteriormente, se entiende entonces que lo primero que hace el autor sea suspender o poner entre paréntesis la circunstancia empírica de la visita y del intercambio con Heidegger como clave para la interpretación del significado del poema, a diferencia de como hace Gadamer (17) - es decir, como veremos de inmediato, a diferencia de la hermenéutica misma. A lo sumo, el poema puede considerarse como el inicio de un "diálogo" que debe permanecer enteramente y por principio venidero, por construir. Es decir, precisamente, no hay "diálogo" alguno -la palabra será insistentemente encerrada entre comillas a lo largo del libro. Celan y Heidegger son, como dice un verso de la pieza aludida, "orquídea y orquídea, solas", o sea comenta Oyarzún-, "vecinas, separadas, únicas, aisladas en su pura singularidad" (11).

Querer averiguar el significado de "Todtnauberg"-el significado del encuentro entre Celan y Heidegger-, en particular averiguar la intención y la experiencia que animaron a Celan en la composición del poema, es una empresa "no sólo ilusoria, sino estéril" (15). Pero esa esterilidad, ilustrada por la lectura de Gadamer, no deja de ofrecerle a Oyarzún la matriz general en que desarrollará su propia experiencia de lectura, cuando no su propia teoría de la lectura. Hay que advertir, en todo caso, que una "mala interpretación" de Gadamer (si es tan mala como a Oyarzún le parece) no tiene por qué justificar una condena general de la hermenéutica. Habría que releer Entre Celan y Heidegger buscando sistematizar las críticas que se dirigen a la hermenéutica, más complejas de lo que parece a primera vista. Sepa el lector que el interés por el estudio de Gadamer no es para nada nuevo en Oyarzún ${ }^{2}$, ni su apreciación tan negativa como en este libro, limitado por lo demás a discutir el texto sobre Celan. De igual forma que la figura de Heidegger, la de Gadamer también se perfila bajo nuevas luces cuando se la examina desde Celan -y lo propio ocurrirá con la de Levinas y la de Derrida, autores discutidos por Oyarzún en su ensayo.

2 Cfr. "Hans-Georg Gadamer: el problema de la conciencia histórico-hermenéutica" (1975) y "Sentido, verdad, hermenéutica" (1976), reimpresos en De lenguaje, historia y poder, Santiago: Departamento de Teoría de las Artes (colección Teoría), 2001, pp. 9-20 y 21-77, así como "Estética y hermenéutica" (Revista de Teoría del Arte. 3: 63-81, Santiago, 2000). 
Sea como sea, la "lectura hermenéutica" es el telón de fondo sobre el cual -o en contra del cual- se elabora la de nuestro autor. De ahí esta tesis: "un poema no quiere decir nada, probablemente porque sólo se escribe un poema cuando se ha anulado, se ha anonadado todo querer" (15). Pero este no querer decir nada del poema no es, para Oyarzún, una ausencia puramente negativa de sentido, un sin sentido sin sentido. Se trata de una "nada de sentido" (13) que pertenece de manera auténtica y propia al sentido mismo del poema. La lectura de Celan es la experiencia de esa falta de sentido, es decir, la experiencia de un lenguaje que nos conduce hacia esa falta, hacia lo que se sustrae a la comprensión, y la interrumpe. El poema es "nada de sentido", porque se trata de un sentido que no acontece en el espacio universal de comprensión (en lo abierto por una precomprensión de la "tradición", por ejemplo, para hablar como Gadamer). "En lo suyo más riguroso e insistente", la poesía de Celan consiste en esta "irrupción de nada" (18). O bien, para decirlo con otro concepto largamente analizado por el autor, el poema es irrupción de lo absurdo: "lo absurdo $a b$-surdus, lo discordante, no en éste o aquel respecto, sino lo esencialmente discordante, aquello que absolutamente no calza con la esencia de la palabra- marca también una afasia fundamental, una supresión de la palabra desde la raíz de su posibilidad" (37).

La investigación de Oyarzún se inicia entonces, y en buena medida se estructura, sobre el fondo de esta discusión frontal con la "abusiva" interpretación que Gadamer ofrece de "Todtnauberg" - el mismo autor declara esta "deuda" en una nota de la página 14. Se trata de poder indicar eso que, en la medida misma en que interrumpe a la comprensión, se da a la comprensión, solo que resistiéndola, exigiéndola, interpelándola. El sentido tiene sentido ante todo allí donde se sustrae a toda significación disponible, a todo universal -ideal, simbólico o ejemplar-; allí donde se "excribe" de la significación inscrita, de la escritura, de la literatura o incluso del lenguaje. "Lo excrito" es un término de Jean-Luc Nancy que Oyarzún emplea varias veces para describir este "fuera del lenguaje" al que nos abre la singularidad radical y absurda del poema. Hay que cuidarse, sin embargo, de entender ese "fuera" como un espacio místico de inteligibilidad no mediada por la significación. Antes bien, se trata de aquello que, en el lenguaje mismo y en virtud de él, queda fuera del universal y fuera del concepto, fuera del símbolo y de la alegoría, fuera del ejemplo, del tropo o de la imagen: "en medio / del remolino de metáforas" (estos versos son de Celan, y se refieren al lugar de la "verdad", como tendremos ocasión de ver más adelante).

Este resto, esta nada que queda fuera del lenguaje (en el lenguaje mismo), es analizada en el capítulo VI a título de "pizca". Con esta palabra Oyarzún traduce el último verso de "Yo tomo vino": "del tambor de las suertes cae / nuestra pizca" (aus der Lostrommel fällt / unser Deut). Decimos "una pizca” para significar lo nimio, lo mínimo, lo insignificante, "una nada" (un rien, como se dice en francés). En sus acepciones usuales, la palabra "Deut" está ligada específicamente a giros sobre una "escasa cantidad de dinero" (117). La pizca es el mínimo que, sin ser nada, sin significar ninguna cosa, no desaparece lisa y llanamente en su no ser. La pizca es una nada que es: ápice de significación que significa lo insignificante como tal. Una "chaucha", dice Oyarzún: "moneda de valor insignificante, circulante que carece de valor de cambio" 
(118) - pero que posee, con todo, ese valor, el de circular sin valor. La pizca es la nimiedad insignificante que, por su impotencia misma a significar, interrumpe y perfora al orden de la significación. La pizca es la "nada de sentido" que irrumpe como nada y que resiste al sentido y a la comprensión -interpelándola, exigiéndola, y por eso, en cierta forma, poniéndola en movimiento: lo que, irrumpiendo en el sentido como sin sentido ( significación. La "pizca” es el "ápice de insignificancia que se aloja en toda significación" (117). La "pizca" nombra lo decisivo en la poesía de Celan, aquello que hace que el poema sea el acontecer de lo absurdo, de la singularidad radical.

En este punto, cabe formular, me parece, una pregunta que podría invitar a una discusión posterior. La "pizca", en tanto que "nada de sentido", debe ser puesta en relación y en tensión con el sentido de ser como nada, es decir, con la diferencia ontológica. El ser no es un ente, el ser no es nada, pero no por eso es "la nada", desapareciendo en una pura negatividad a-significante. El ser es lo que, en su retiro -no "siendo" nada, o en su diferencia respecto del ente-, le transfiere al ente su ser: que el ente es. Ser es el movimiento mismo de ser del ente, movimiento que "trasciende" al ente y a cualquier significación óntica (tal trascender es el "sentido de ser"). Todo indica que el ser es, entonces -y esto es lo único que el ser podría "ser"-, una pizca de ser. Si esto es así, no se entiende bien en qué sentido Oyarzún distingue - ¿a instancias de Levinas?la pizca del ser, no se entiende en qué sentido la pizca está más allá o más acá del ser: "nada-de-ser, y no (ser como) nada-de-ente: es el Deut, la insignificancia, la 'chaucha'; lo sin valor, que se hurta, a la vez, a toda ontología y a toda axiología" (119). Pero el "ser", que no es nada, precisamente no es, tampoco, un valor...

Vuelvo al argumento de Oyarzún. ¿Cómo se manifiesta la pizca, la insignificancia? Pero, ¿cómo siquiera podría "manifestarse", "aparecer", "mostrarse”, si como tal queda sustraída al sentido y a la comprensión? En el dolor. El dolor, en cuanto dolor, no es significante. O mejor: el dolor, lo doloroso del dolor, es precisamente su insignificancia, su insensatez. En cuanto tal, el dolor no se deja subsumir como la figura de una mediación dialéctica, no se deja relevar por la lógica perversa de una significación sacrificial. En cuanto tal, el dolor es aquello que excede al sentido, exceso insensato que resiste y se impone con la impotencia propia de su silencio absoluto. "El dolor habla en el silencio, como silencio, habla silencio" (93). Oyarzún reseña con precisión los análisis de Heidegger sobre el dolor en De Camino al habla (a propósito de Trakl). El dolor escinde, el dolor es di-ferencia (Unter-schied). Sin embargo, esta di-ferencia no es ajena a la esencia reuniente del logos (96), que desde luego ofrece otra cosa que una "dialéctica" del dolor. En Heidegger, el dolor es una reunión de/en la es-cisión, vale decir, "lo articulador en el desgarrar que separa-y-reúne"3. En

3 Recuerdo brevemente uno de los textos de De camino al habla comentados por Oyarzún: "El dolor es lo articulador en el desgarrar que separa-y-reúne. El dolor es la articulación (die Fuge, la juntura) del desgarro. Ella es el umbral. Ella soporta el Entre, la mitad de los dos separados en ella. El dolor articula [junta] el desgarro de la di-ferencia. El dolor es la di-ferencia (Unter-schied, es-cisión) misma” (Unterwegs zur Sprache, Pfullingen: Neske, 1971, p. 27, texto citado y traducido en la pág. 99). 
Celan, en cambio, el dolor se sustrae a esta esencia reuniente de la diferencia. El dolor es una pura herida (volveré enseguida sobre la "herida", que Oyarzún analiza a propósito de "lo crudo" en el poema "Todtnauberg") que ni siquiera tiene el sentido de un desgarro, que ni siquiera dispone del sentido - del lenguaje, del poema- del dolor. El dolor es juntura de lo separado en cuanto tal, de lo separado en su radical indiferencia, insignificancia. "En Heidegger, todo lo que pudiera concebirse como herida es remitido al dolor, y no a la inversa: hay herida a partir del dolor (lo propio de éste es el desgarro, que separa y escinde); esta remisión es esencial para la comprensión heideggeriana del dolor como articulación de reunión y apartamiento; y, por cierto, la base de esta comprensión es clara: Heidegger interpreta la herida desde su sentido, es decir, desde su primaria incorporación al lenguaje. ¿Será que en Celan hay una anterioridad indeleble de la herida, que marca toda experiencia con el trazo de la escisión?" (104).

Como horizonte problemático para sus análisis sobre el dolor, Oyarzún escoge un concepto extremadamente difícil para Heidegger, casi desaparecido de su vocabulario filosófico: el concepto de cuerpo. El cuerpo es lo expresado en el dolor, como dolor. O mejor, el cuerpo es la comparecencia del dolor, su resistencia -y su impotencia-, su existencia y exposición. "En este silencio [del dolor], que no confundiremos con reticencia o con reserva -inhibición que un hablante inflige a su discurso-, se excribe el cuerpo como memento y momento de mortalidad" (95). El cuerpo pertenece, en ese sentido, a una dimensión pre-lingüística, pre- o an-humana, que me precavería de llamar, sin embargo, "animal”: se trata más bien del lugar mismo de la existencia, del sinsentido aconteciendo en el lenguaje. "Quizá toda anterioridad del lenguaje, quizás toda an-humanidad del lenguaje (...) no radique sino precisamente en esta siempre previa insistencia del cuerpo" (93). El cuerpo del dolor no es entonces el cuerpo origen de la significación, no es la corporalidad viviente insuflando sentido al mundo sensible, carne fenomenológica vivida en la íntima reflexión del propio cuerpo. $\mathrm{Ni}$ siquiera estamos hablando lisa y llanamente de un cuerpo vivo (es memento y momento de mortalidad). Estamos hablando más bien de un cuerpo herido, y herido a muerte, cuerpo muerto, cuerpo que pierde sangre, es decir -porque está muerto- no perdiendo nada ya. Pérdida perdida, insignificante, inespiritual, insacrificial, insensata, absurda: lo crudo. Lo crudo es "carne viva", cierto, pero en el sentido de una vida de la carne que ya no puede ser vivida por ninguna conciencia o corporalidad viviente. Es lo muerto en su estado cruento, es "la llaga misma", en sí misma. "Lo crudo: la carne viva, sangrante, que sigue testimoniando vida aún en la muerte, porque sangra; lo crudo: la llaga misma. ¿Misma? Pero ¿no se la haría -así- pensable, no es acaso - llamarla 'misma', pensarla 'en sí misma' y 'como tal'- ya empezar a restañarla?" (19). Sobre todo, entonces, lo crudo es el nombre para la herida que no cierra, para la herida que ni siquiera tiene el sentido ("articulador en el desgarrar que separa-y-reúne") de una herida.

Nada se funda sobre esa herida. Pues para fundar, para instituir, para crear -la historia, la comunidad-, la herida debe dejar de ser mera herida y debe poder incorporarse al sentido. Cruda, la herida se ex-cribe de la historia y de la comunidad, se excribe incluso de su nombre de "herida", y de todos los nombres que la nombran, para 
dejarla abierta o para cerrarla, para endeudarnos o para cicatrizarnos: "Shoah", "holocausto", "exterminio", "mal", etc. Cruda, la herida se ex-cribe de todos los nombres del hombre para la insensatez de su historia. A propósito de "Todtnauberg", Oyarzún escribe: "De ahí que ni el exterminio del pueblo judío, que enmudece la palabra del poeta, ni la adhesión al nazismo, que permanece indeleble en el silencio del pensador, sean 'referencias' que permitan despejar qué significa aquí lo 'crudo' (si algo significa) y, con ello, la relación entre Celan y Heidegger. Todo intento de nominación, todo historiar este abismo oblitera lo crudo (...). Ni habla Celan como portavoz del pueblo judío, ni calla Heidegger como síntoma del pueblo victimario" (19-20). Si no se entiende esto, si no se atiende a la dimensión problemática que tienen, para nosotros, los nombres de la herida, no podremos entender por qué lo crudo resiste a todo sentido que intentemos otorgarle, por qué retorna, por qué se incrusta en la memoria, y obliga a pensar.

La Shoah - pero se trata de lo que queda fuera de este nombre- es sin duda una herida que sigue sangrando, que nunca dejará de sangrar. Esa sangre no se recupera, sin embargo, ni se representa, ni se conmemora. Su pérdida se pierde, se sincopa su posibilidad de destino. Y tal es el único comienzo posible de la historia. El tiempo -la historia-se temporaliza precisamente porque nunca, en ninguna parte, estará presente un presente preñado de destino. Por eso, en lugar de fundarse -y de conmemorarse-, la historia se fecha, se data. La data no data lo que estuvo presente. A "lo que" se data en la data nadie asiste, nadie nunca asistió, ninguna conciencia individual o colectiva ("nadie / atestigua por el / testigo"). La data, al no datar nada, data la nada, la sustracción a la conciencia histórica. Eso es pensar radicalmente la temporalidad y la historicidad, tiempo que se temporaliza en la medida misma en que no transcurre para ninguna conciencia. Tiempo sin tiempo y sin transcurso que vuelve a la vuelta del año (42), indiferente a la diferencia temporal vivida en la intimidad de una conciencia. La data es la que vuelve, y no "lo que" ella data: vuelve la vuelta, el retorno mismo (¿acaso no es eso lo traumático del trauma, nunca "lo que" retorna, sino el hecho de que retorne, sustrayéndose a sus sentidos, desafiando a nuestra comprensión?). La data mantiene respecto del sentido del acontecimiento "una suerte de extraña indiferencia, en virtud de la cual, no obstante, puede marcar precisamente la diferencia que hace el acontecimiento, al señalizar su irrupción en el tiempo, como tiempo" (43). La data data el acontecer del tiempo, irrumpiendo desde fuera de la conciencia (del transcurso presentable en un presente, por distendido y complejo que éste sea) y de la comunidad. La data: el acontecer del acontecer: que algo acontece -suspendido qué sea eso, interrumpido el sentido de lo que acontece-, pizca para la cual no hay ningún presente disponible.

Ciertamente, lo que queda lo fundan los poetas. "Lo que queda" es la pizca inscrita/excrita en el poema y que funda historia solo en la medida en que despoja al evento de todo sentido, en que impone -impotente- la imposibilidad de ser conmemorada, la imposibilidad de atestiguar por lo que hubo, por quien estuvo. La poesía resiste tenazmente a toda institución de sentido, y además exige -impotente, insignificante- que destituyamos todo sentido que amenace obliterarla. Funda en la medida en que desfunda, en que se vuelve posibilidad de aquello que excede toda expectativa, 
todo programa, toda esperanza, toda comprensión y todo porvenir: aquello que siempre queda siendo inminencia por venir (¿la tarea, la ley de la lectura?). "La palabrapoema, enviada a ciegas, desde un parpadeo del tiempo absolutamente puntual, irrepetible, librada a su destino incierto, pero también a la tenacidad de su dirección en busca de algo abierto y ocupable, que es, a un tiempo, la tenacidad de su propia apertura y vacancia para el advenimiento de otra palabra, de la palabra del otro (¿y del otro como palabra?), no se encuentra con ésta, no se toca con ésta, porque permanece ausente, reservada, terca" (21).

El poema data la insignificancia inconmemorable del dolor. Data lo que queda, y que queda porque queda fuera del sentido. El poema es entonces el lugar de lo crudo, el cuerpo. "Lo que queda" (was bleibet), escribe Oyarzún comentando el verso de Hölderlin, significa "no lo que no abandona el lugar preservándolo, sino lo que queda como resto, como pequeño resto, resto de la vida (Leben), de cuerpo (Leib)". El autor subraya el parentesco etimológico de estos conceptos (Leben, Leib) con el verbo bleiben, permanecer, quedar (48).

Me parece interesante notar la relevancia que la figura del "planeta" podría adquirir en el pensamiento poético de Celan a través de algunos análisis de Oyarzún. Ni Celan ni Oyarzún hablan del "planeta”, cierto, pero sí del "meridiano". El Meridiano es el título de un discurso de Celan pronunciado a propósito de la recepción del premio Georg Büchner en octubre de 1960, y es acaso el texto más analizado por Oyarzún en su libro. El "meridiano" es la dimensión ("inmaterial” y "terrestre") del globo planetario, la "máxima distancia y recorrido, trayecto, el mayor de todos, total, que "vuelve sobre sí mismo a través de ambos polos"” (29). El planeta es el lugar de todos los lugares, el mapa de todos los mapas (sobre el "mapa" en Celan, cfr. pp. 2931). Es la condición de posibilidad de la data y de su retorno. El planeta-que Heidegger considera la imagen de la más desterrada existencia- puede contraponerse al concepto fenomenológico de "mundo". El mundo es apertura y horizonte, correlato de un aquí absoluto o de un punto cero vivido en la proximidad absoluta de sí (propio cuerpo o propia conciencia). El planeta, en cambio, es indiferente a todo aquí y todo allá. En el planeta, ningún punto es más próximo ni más lejano que otro, ningún punto asiste a sí mismo sin implicar la distancia que lo separa de los otros puntos o la distancia máxima que lo separa de sí mismo. El planeta es incluso indiferente al ahí de la existencia (Da-sein), es decir, al lugar impropio en que me encuentro lanzado con la tarea de ser. El planeta es, acaso, el lugar del poema: lugar al que nadie asiste, lugar sin lugar (sin aquí, allí o ahí) que inscribe/excribe lo que queda del cuerpo y del dolor. El poema es un lugar que no-está-en-el-mundo, que se sustrae a todos los lugares y a todos los tiempos. Fuera-del-mundo, fuera-del-tiempo, fuera-del-espacio: u-tópico, para decirlo con otro concepto importante de El Meridiano analizado en el libro de Oyarzún (pp. 36 ss y 39 ss).

Por otro lado, hay un tema que, a pesar de permanecer relativamente al margen en el ensayo de Oyarzún, merecería sin duda todo un desarrollo aparte: la percepción. Sobre ella se habla a propósito del análisis de la metáfora y la imagen poética, hacia el último tercio del capítulo "Lenguaje” (en particular pp. 83-92). Leemos en El Meridiano: “¿Y qué serían las imágenes? Lo percibido y por percibir por única vez, siempre 
de nuevo por única vez y sólo ahora y sólo aquí”. Una percepción que solo ocurre aquí y ahora por única vez, porque nada ni nadie -un cuerpo viviente o una conciencia percipiente- atestigua por ese aquí y por ese ahora, precisamente no es una percepción. Se trata entonces de un encuentro u-tópico (sin aquí y sin ahora, sin horizonte de experiencia, sin condición trascendental) con lo percibido, "contacto absoluto del percipiente con su tiempo, como la 'vez' de una total irrupción” (83). "La Wahrnehmung no es posesión o la asimilación (Aufnahme) de algo o de alguien en una figura pre-diseñada, pre-sabida y en cuanto tal verdadera (por su congruencia con un patrón preestablecido), sino la apertura a la diferencia, a la alteridad radical, es decir, a su excepción (Ausnahme): si 'percibir' es 'tomar', éste requiere ante todo exponerse 'afuera"' (86, nota). La imagen del poema -al igual que la data- no presenta, no imagina, no configura, no esquematiza nada. No es ni la idea ni el simulacro de lo real (84, nota). No media, no traslada, no metaforiza nada. En suma, otra vez: no significa nada -a no ser precisamente esa pizca imperceptible que es la "nada de sentido". La imagen, en vez de figurar la verdad, la deja aparte de toda figuración, ex-crita "en medio del remolino de metáforas", desalojada de todo claro y de toda revelación: en el punto en que se fuga toda luz y se impone -impotente- una nitidez invisible (la “forzada luz", Lichtzwang, que habría que oponer aquí a la Lichtung con que Heidegger describe el des-ocultamiento del ente). La verdad no se lee, ni se comprende: se la encuentra, se la percibe, acontece ahí donde se perfora toda imagen y toda figuración.

Se entiende que no es jugando con las palabras que Oyarzún describe el encuentro, el momento mismo (u-tópico) del encuentro, como la imposibilidad de un encuentro: "Un encuentro sin encuentro, sin diálogo" (17). Un encuentro sin encuentro significa un encuentro que acontece más allá de un espacio de encuentro, de un horizonte común (tradición o lengua comunes, por ejemplo). Un encuentro fuera del mundo, sin apertura previa que lo posibilite - un encuentro que engendra, con su evento mismo, su posibilidad. Más aun, un encuentro - es lo propio de un evento- cuya única condición de posibilidad es la carencia de condiciones de posibilidad: encuentro im-posible (para hablar como Derrida) que ocurre cuando nada -ningún sentido, ninguna verdad, ninguna tradición, ninguna experiencia, ningún horizonte- hay en común, cuando nada hay entre yo y tú: "sólo la Nada estaba entre nosotros, nos hallábamos / enteramente juntos" ("Tantas estrellas", 132). Este encuentro imposible se estructura, por último, no en el "diálogo", sino en el proferir, vale decir, donde yo se ex-cribe y ex-cribe al tú implicado en ella: "un 'fuera' que anuncia su llegada diciendo, entrecortadamente, 'yo', un 'fuera' invocado en el 'tú' -acaso un 'fuera' pro-nominal, pre-nominal” (113). Antes de hablar, y en cada palabra proferida, yo y tú se encuentran y se regalan la imposibilidad de este encuentro, se regalan la singularidad radical de cada uno ("orquídea y orquídea, solas"), la "estrechez más propia” en que consiste la existencia. 